\title{
Narrativas das experiências de aprendizagens vividas na educação profissional e
} tecnológica pelos alunos do PROEJA

\author{
Narratives of learning experiences experienced in professional and technological education by \\ PROEJA students
}

Narrativas de experiencias de aprendizaje experimentadas en la educación profesional y

tecnológica por estudiantes de PROEJA

Recebido: 18/11/2021 | Revisado: 27/12/2021 | Aceito: 17/12/2021 | Publicado: 25/12/2021

\author{
Sandra Maria Campos Alves \\ ORCID: https://orcid.org/0000-0002-9343-9324 \\ Instituto Federal de Educação, Ciência e Tecnologia do Rio Grande do Norte, Brasil \\ E-mail: sandra.campos@ifrn.edu.br \\ Ketúcia Mirlene Duarte de Lima \\ ORCID: https://orcid.org/0000-0001-6142-8156 \\ Universidade Estadual do Rio Grande do Norte, Brasil \\ E-mail: kmduartelima@hotmail.com
}

\begin{abstract}
Resumo
O trabalho teve como propósito articular as histórias de vida dos alunos do PROEJA com suas experiências vividas na EPT, no qual buscamos demonstrar quais os impactos do referido curso na vida desses sujeitos e culminou com um produto educacional na forma de um curta-metragem. Para fundamentar teoricamente essa pesquisa, lançamos mão de estudos acerca das práticas pedagógicas da EJA no Brasil, bases conceituais da Educação profissional e Tecnológica e sua contextualização com a EJA, concepção de Ensino Médio Integrado, além de tratar sobre a experiência do trabalho metodológico com a memória. Utilizamos a história de vida como procedimento operacional (Severino 2002), e para o estudo dos dados captados através do curta-metragem, no qual possibilitou identificar categorias de análises, a saber: trabalho, família, dificuldades e preconceitos, concretização de sonhos), utilizamos a análise do discurso (Bartelmebs 2013). A partir das análises realizadas foi possível visualizar que, o curta-metragem serviu como fonte de inspiração e motivação para os alunos do PROEJA do IFRN, campus Mossoró. Desse modo, observamos que o curta-metragem apresentado cumpre a função de promover um vinculo entre as historias de vida dos sujeitos projetados no vídeo e dos estudantes do PROEJA, motivando estes a seguirem na conclusão de seu curso.
\end{abstract}

Palavras-chave: PROEJA; Ensino médio integrado; Curta-metragem; Análise do discurso.

\begin{abstract}
The work aimed to articulate the life histories of PROEJA students with their experiences in the PtSD, in which we sought to demonstrate the impacts of this course on the lives of these subjects and culminated in an educational product in the form of a short film. To theoretically support this research, we used studies on the pedagogical practices of the EJA in Brazil, conceptual bases of professional and technological education and its contextualization with the EJA, conception of Integrated High School, besides dealing with the experience of methodological work with memory. We used life history as an operational procedure (Severino 2002), and for the study of data captured through the short film, in which it made it possible to identify categories of analyses, namely: work, family, difficulties and prejudices, realization of dreams), we used discourse analysis (Bartelmebs 2013). From the analyses performed it was possible to visualize that the short film served as a source of inspiration and motivation for the students of THE PROEJA of IFRN, Mossoró campus. Thus, we observed that the short film presented fulfills the function of promoting a link between the life histories of the subjects projected in the video and the students of PROEJA, motivating them to follow the completion of their course.
\end{abstract}

Keywords: PROEJA; Integrated high school; Short film; Discourse analysis.

\section{Resumen}

El trabajo tuvo como objetivo articular las historias de vida de los estudiantes de PROEJA con sus experiencias en el PROEJA en el que se buscó demostrar los impactos de este curso en la vida de estos sujetos y culminó en un producto educativo en forma de cortometraje. Para apoyar teóricamente esta investigación, utilizamos estudios sobre las prácticas pedagógicas de la EJA en Brasil, bases conceptuales de la educación profesional y tecnológica y su contextualización con la EJA, concepción de la Escuela Secundaria Integrada, además de tratar la experiencia del trabajo metodológico con la memoria. Utilizamos la historia de vida como procedimiento operativo (Severino 2002), 
y para el estudio de los datos capturados a través del cortometraje, en el que se lograron identificar categorías de análisis, a saber: trabajo, familia, dificultades y prejuicios, realización de sueños), utilizamos el análisis del discurso (Bartelmebs 2013). A partir de los análisis realizados se pudo visualizar que el cortometraje sirvió de fuente de inspiración y motivación para los alumnos de EL PROEJA de IFRN, campus Mossoró. Así, observamos que el cortometraje presentado cumple la función de promover un vínculo entre las historias de vida de las asignaturas proyectadas en el video y los estudiantes de PROEJA, motivándolos a seguir la realización de su curso.

Palabras clave: PROEJA; Escuela secundaria integrada; Cortometraje; Análisis del discurso.

\section{Introdução}

Buscando intervir no mundo, nos lançamos a pensar sobre a ação política e transformadora, na qual chamamos de Educação, em especial a educação destinada a jovens e adultos, cuja análise do ponto de vista pedagógico, requisitou uma prévia situada no campo da economia política, como forma de possibilitar uma compreensão das agendas políticas que permearam a EJA no Brasil ao longo da sua trajetória.

De acordo com Cambi (1999), o século XIX foi marcado pela ascensão da burguesia ao poder, mas foi também um período em que ela vivenciou seu grande temor que, em virtude do surgimento das ideias socialistas e comunistas na metade desse mesmo século, fez surgir uma frente de oposição à luta de classes. Esse novo arranjo promoveu uma enorme zona de tensão social, em que se investiram as ideologias, as políticas, a própria cultura, além da vida social e econômica.

Araújo (2017) analisa a trajetória da educação no Brasil no âmbito do contexto da luta de classes e condicionada a uma base material, que a insere entre os conflitos e as propostas do modo de produção capitalista. Segundo a autora, a educação formal no Brasil surge com a finalidade de atender aos interesses de uma elite agrária, que passa a utilizá-la como forma de disciplinar a classe trabalhadora ampliando funções ideológicas e colocando na grande massa valores e normas dominantes.

Esse parece ser o pensamento que influenciou as diferentes modalidades de ensino no país, em especial a Educação de Jovens e Adultos, conforme Almeida e Corso (2015) identificam na sua trajetória, no tocante a ações e programas destinados à Educação Básica e, em particular, aos programas de alfabetização para o combate ao analfabetismo. Dentre essas ações também estava presente o incentivo a profissionalização, ainda que de forma tímida. Ou seja, uma educação para os filhos da classe trabalhadora com propósitos bem diferente da educação voltada a classe dominante.

Diante disso, nos colocamos em defesa de uma concepção de Educação de Jovens e Adultos, fundamentada no princípio da politecnia, cuja proposta de educação é a formação humana integral dos estudantes, visando superar a dualidade entre uma educação propedêutica destinada às classes favorecidas e uma educação de cunho profissionalizante destinada à classe trabalhadora.

No que concerne a essa integração tão importante para romper com as agendas políticas destinadas a EJA no Brasil, Sa et al. (2020) compreendem que o ensino integrado é a integração entre a denominada educação geral (Ciências, Letras e Artes) e a formação profissionalizante, desenvolvida em um currículo único na mesma instituição educacional, tendo como referência conceitual a formação integral dos sujeitos.

E para este propósito, nosso estudo pretendeu destacar o caráter político e social da Educação de Jovens e Adultos EJA, no tocante as experiências de aprendizagem vividas na EPT pelos estudantes do PROEJA, cuja concepção de ensino é pautada por um ideal de formação humana em sua totalidade. Assim, buscamos responder a seguinte questão: até que ponto as histórias de vida de alunos egressos do PROEJA podem contribuir com a função de inspirar e motivar jovens e adultos que buscam o PROEJA para concluir sua formação humana e profissional?

Julgamos esse questionamento pertinente, pois acreditamos existir um elo entre esses sujeitos acerca das suas histórias de vida. Quer seja por uma trajetória marcada pela exclusão escolar, ou pelo anseio por escolarização e profissionalização, fator determinante para jovens e adultos que buscam se inserir no mercado de trabalho, depois de anos fora de um ambiente 
escolar.

É a partir dessa realidade que compreendemos a EJA, cuja trajetória tem demonstrado que essa modalidade de ensino, além de fazer parte de ações descontínuas, é marcada por uma diversidade de programas de governo que sempre visaram atender as demandas de mercado, sem se preocupar com a formação humana integral desses sujeitos. Haddad e Del Pierro (2000) corroboram com esse entendimento ao apontar que historicamente as ações direcionadas a modalidade de educação destinada a jovens e adultos foram desenvolvidas por meio de programas, campanhas e de projetos fragmentados, além de ações focalizadas e desarticuladas que não conseguiam garantir o direito à educação no horizonte de universalização.

Viera (2004) aponta indícios desse cenário ao indicar, por exemplo, que com a criação da Secretaria Extraordinária de Erradicação do Analfabetismo, no ano de 2003, ocorreu o lançamento do denominado Brasil Alfabetizado que contava com os seguintes projetos: Projeto Escola de Fábrica, com foco na oferta de cursos de formação profissional, e o PROJOVEM que também apresentava o viés de qualificação para o mercado de trabalho. Levar os alunos da EJA a refletirem sobre suas experiências de aprendizagens na EPT, através das histórias de vida de alunos egressos, fará perceber a relevância desse programa para a sua formação humana integral.

Destarte, procuramos enriquecer a discussão em torno da EJA a partir do PROEJA, que parte de uma proposta de integração da educação profissional à educação básica, cujos objetivos vão desde a inclusão social por meio da capacitação para o trabalho, até a elevação da escolaridade. Para isso, utilizamos as histórias de vida dos alunos da EJA articuladas com suas experiências vivenciadas na EPT.

Esse debate, frente ao trabalho de natureza metodológica que desenvolvemos a partir das memórias dos alunos do curso técnico em Edificações na modalidade PROEJA do IFRN, Campus Mossoró, através das suas histórias de vida, contribuiu para a construção de respostas para diversos desafios enfrentados pela EJA. De acordo com Pollak (1989), estudar as memórias coletivas fortemente constituídas como memória nacional implica preliminarmente a análise de sua função.

Assim, analisar a Concepção de Ensino Médio Integrado, a partir das histórias de vida dos alunos do curso de Edificações do IFRN, Campus Mossoró, na modalidade EJA, possibilitou uma reflexão crítica acerca de aspectos presentes em seus discursos, tais como trabalho, família, dificuldades e preconceitos, e concretizações de sonhos. Aspectos esses, que se apresentam como responsáveis pelo afastamento e pela inserção desses sujeitos de um ambiente de sala de aula.

Trazer à luz as histórias de vida de jovens e adultos, que por inúmeras razões precisaram abandonar seu processo formativo ou não tiveram acesso a uma educação formal fez parte do enquadramento que pretendíamos estabelecer a partir das memórias de alunos egressos do PROEJA, visando reinterpretar o passado em função de embates travados no presente. Para esse embate, o Programa Nacional de Integração da Educação Profissional com a Educação Básica na Modalidade de Educação de Jovens e Adultos (PROEJA), criado inicialmente em 2005 pelo Decreto n ${ }^{\circ}$. 5.478, de 24/06/2005, revogado posteriormente pelo Decreto $\mathrm{n}^{\circ} 5.840$, de 13 de julho de 2006, possibilitou reinterpretar a trajetória desses sujeitos marcada pela exclusão escolar.

Nessa direção, entendemos que, muito mais que uma modalidade de ensino, dentre as variadas práticas pedagógicas existentes, a EJA nos revela uma agenda política que nega a luta de jovens e adultos por uma educação de qualidade, pública, gratuita e com as especificidades que esse público em especial exige, visto que são trabalhadores, na sua grande maioria, que em algum momento da sua trajetória de vida precisaram abandonar sua formação escolar em idade regular, estabelecida pelo sistema educacional brasileiro. O Parecer 11/2000 aponta que a Educação de Jovens e Adultos representa, portanto, uma dívida para aqueles que, em razão das mais diversas expressões da questão social, tiveram negado o acesso à educação formal (Brasil, 2002).

Acerca disso, inferimos que o papel social do PROEJA, enquanto proposta educacional voltada para jovens e adultos excluídos socialmente, é justamente uma prática em prol da justiça social, visto que, do ponto de vista da natureza do seu 
objeto, esse programa visa oportunizar a alunos portadores de diploma do ensino fundamental, que não tenham concluído o ensino médio, a concluírem seus estudos e se qualificarem profissionalmente.

De acordo com Moura e Henrique (2012), o PROEJA surgiu apresentando uma dupla finalidade, a saber: enfrentar o contexto histórico mencionado anteriormente, com marcas de descontinuidades e focalização, e aliar a educação básica a formação profissional com o intuito de contribuir para integração socioeconômica de qualidade de sujeitos jovens e adultos na sociedade, a fim de proporcionar melhores condições em aspectos como participação social, política, cultural, sem esquecer do mundo do trabalho por meio da elevação de escolaridade.

Sendo assim, este programa nacional cria a possibilidade de concebermos as Instituições Federais de Educação Profissional e Tecnológica como um espaço público, pois permitirá a inserção desta parcela de jovens e adultos nestas unidades escolares, garantindo-lhes o direito à educação gratuita, pública e de qualidade, na perspectiva de integralidade da formação escola (Paula \& Schlaucher, 2020).

Acerca desses desafios, para concretização de um Ensino Médio Integrado, principalmente na modalidade EJA, nosso objetivo junto às turmas do curso de Edificações na modalidade PROEJA foi justamente trazer essa problemática aos alunos através de uma pedagogia da pergunta, para que os próprios alunos, ao tentar responder questionamentos essenciais, construam novas perguntas e teorizem o EMI no âmbito da Educação de Jovens e Adultos como concepção de formação humana omnilateral.

\section{Metodologia}

O estudo foi realizado através de uma pesquisa qualitativa com base na narração das histórias de vida de egressos do curso de Edificações na modalidade EJA, do IFRN, Campus Mossoró, com enfoque nas experiências vividas na Educação Profissional e Tecnológica - EPT.

Acerca da abordagem qualitativa, Godoy (1995) compreende que esse tipo de pesquisa ocupa um reconhecido lugar entre as várias possibilidades de se estudar os fenômenos que envolvem os seres humanos e suas intrincadas relações sociais estabelecidas em diversos ambientes.

Desse modo, inicialmente nos preocupamos em realizar revisão bibliográfica a partir de autores e pesquisadores que discutem as bases conceituais da Educação Profissional no Brasil, a concepção de Ensino Médio Integrado com base no princípio da politecnia e a contextualização da Educação de Jovens e Adultos - EJA no Brasil.

Em seguida, utilizamos a história de vida como procedimento operacional, pois, de acordo com Severino (2002), estas são capazes de favorecer a coleta de informações sobre vida pessoal de um ou vários informantes, podendo assumir formas variadas, como autobiografia, memorial, crônicas, em que se possam expressar as trajetórias pessoais dos sujeitos.

Para o estudo dos dados captados foi utilizado à análise de discurso, visto que para Bartelmebs (2013), quando o pesquisador opta pela entrevista para sua coleta de dados, já de antemão, deve saber que sua análise será de discursos e, por conseguinte, mais detalhada sobre um determinado problema.

Visto que para Caregnato e Multi (2006), o processo de análise discursiva tem a pretensão de interrogar os sentidos estabelecidos em diversas formas de produção, que podem ser verbais e não verbais, bastando que sua materialidade produza sentidos para interpretação. Logo, refletir sobre o PROEJA proporcionará aos alunos do Curso Técnico de Edificações na modalidade EJA, produzirem sentidos acerca das suas experiências de aprendizagens durante o curso e da sua trajetória escolar.

Devido à realidade de enfrentamento da pandemia do novo coronavírus (COVID-19) e o desenvolvimento de uma pesquisa requerer uma série de exigências, o estudo em destaque foi efetivado de modo a cumprir com o distanciamento social, atualmente método mais eficaz contra propagação do vírus. 
A pesquisa que teria como lócus o espaço físico do Instituto Federal de Educação, Ciência e Tecnológica do Rio Grande do Norte campus Mossoró (Foto 1). Situado no endereço Rua Raimundo Firmino de Oliveira, 400 - Conjunto Ulrick Graff, Mossoró - RN, CEP: 59628-330 sofreu adaptações necessárias à adequação ao momento vivenciado. Dentre os Cursos Técnicos Integrados, temos a oferta do Curso Técnico em Edificações na modalidade EJA, com um total de 59 (cinquenta e nove alunos) alunos matriculados no ano de 2021, distribuídos em quatro turmas de PROEJA que correspondem ao $2^{\circ}, 4^{\circ}, 6^{\circ} \mathrm{e}$ $8^{\circ}$ período. O Campus também conta com a atuação de 99 (noventa e nove) Docentes e 61 (sessenta e um) Servidores Técnicos Administrativos, e com um total de 1.957 Discentes matriculados conforme dados fornecidos pela instituição, através do seu setor pedagógico.

Desse modo, para participação na construção do curta-metragem "Construindo Histórias: Narrativas dos alunos egressos do PROEJA no IFRN, Campus Mossoró", produto educacional desta pesquisa, foram selecionados 03 (três) egressos do curso Técnico em Edificações na modalidade de Educação de Jovens e Adultos do IFRN - Campus Mossoró. Com eles as atividades de gravação foram realizadas em locais de suas preferências e levando em conta que, conforme Aquino et al. (2020), entre as estratégias de controle da pandemia, a primeira medida a ser adotada é o distanciamento social que tem como objetivo reduzir interações entre a comunidade, evitando, portanto, aglomerações. Nesse sentido, cabe destaca a etapa de gravações foi realizada de maneira individual e mantendo no mínimo um metro e meio de distância entre os envolvidos no processo.

A etapa de aplicação do produto educacional foi integralmente realizada de forma remota, contando com a participação de discentes de quatro turmas, também do curso Técnico em Edificações na modalidade EJA, do IFRN - Campus Mossoró, matriculados nos $2^{\circ}, 4^{\circ}, 6^{\circ}$ e $8^{\circ}$ períodos, totalizando 30 participantes, que concordaram em fazer parte desse estudo.

A escolha do público-alvo partiu da relevância de voltar o olhar para a realidade de sujeitos que historicamente são postos à margem da sociedade. E o lócus foi escolhido como forma de compreender como vem se comportando essa modalidade que, originária do Decreto $n^{\circ} .5 .478$, de 24/06/2005, "expôs a decisão governamental de atender à demanda de jovens e adultos pela oferta de educação profissional técnica de nível médio, da qual, em geral, são excluídos, bem como, em muitas situações, do próprio ensino médio" (Brasil, 2007, p.12).

Partindo para o processo de produção dos materiais educativos, Kaplún (2003) aponta que a criação de um material educativo se baseia em uma aventura composta pela criação do próprio material e pela criação das possibilidades de utilizações posteriores. O autor, ao tratar sobre a etapa de criação, deixa claro que nessa etapa deve constar o que ele denomina como eixos para análise e construção de mensagens educativas.

Enquanto produto educacional, o curta-metragem tratou de subsidiar experiências de aprendizagem no momento da sua aplicação, dando aos alunos, durante um debate, momentos de fala, para que eles possam se posicionar de forma crítica e reflexiva acerca do conhecimento construído. Logo, essas experiências de aprendizagem transcreveram o eixo pedagógico do curta-metragem.

\section{Resultados e Discussão}

Nesse espaço temos o intuito de discorrer a respeito das histórias apresentadas pelos egressos participantes, buscando articular suas falas e reflexões com os objetivos e concepções estruturantes desse trabalho.

Para isso contamos com a participação de três alunos egressos. A saber: Sandra Lúcia do Nascimento, 59 anos; Shirley Costa Silva, 46 anos, encarregada de manutenção no setor da construção civil; e Francisco Flaviano de A. Pereira , 31 anos, bacharel em Engenharia Civil e servidor público em Aracati-CE, trabalhando na área decorrente do curso técnico do IFRN.

A partir de suas falas apresentaremos categorias de destaque notório, a saber: trabalho, família, retorno ao ambiente escolar, dificuldade, preconceitos e concretização de sonhos. 


\subsection{Trabalho}

Aspectos referentes ao trabalho estiveram presentes durante a gravação dos três depoimentos. Surgindo como aspecto diretamente responsável por afastamento do ambiente escolar, mas também como aspecto capaz de despertar um pensamento reflexivo e encorajador quanto à necessidade de retorno das atividades escolares.

"Eu fiz magistério incompleto. Tive que sair para trabalhar porque tinha que trabalhar para sobreviver. A dificuldade era muito grande. Passei 26 sem estudar. Eu trabalhava no fórum, como copeira. Sempre passava em frente ao IFRN e dizia: "Como eu gostaria de estudar num lugar desses, de fazer um curso" (Egressa Sandra).

Com base no exposto é necessário refletir sobre os motivos que levam jovens e adultos a abandonarem a escola no “tempo regular". A fala de alguns estudiosos sobre o tema é unânime ao afirmar que o índice de evasão escolar é reflexo de aspectos sociais como determinantes. Para comprovar isso podemos recorrer a Almeida e Corso (2014) que tratam da evasão dos alunos da EJA como um complexo construto social e apontam como causas relacionadas à desistência da educação questões das mais diversas ordens.

Ao tratar da evasão e relacionar sua causa aos mais diversos fatores, devemos levar em consideração que estes podem advir de causas internas como também externas ao ambiente escolar. Diversos estudos têm tratado sobre esse assunto e apontam como aspectos sociais determinantes da evasão escolar as políticas governamentais (ou falta delas), o desemprego, baixo desempenho e reprovação (Malafaia, 2008; Digiácomo, 2005). Além dos problemas supracitados, os problemas de ordem familiar também fazem parte desse contexto e, por isso, trataremos sobre essa categoria a seguir.

\subsection{Família}

A temática família foi questão recorrente nas falas das participantes mulheres, para nós isso denota a centralidade que, historicamente, essa questão representa na vida das mulheres.

Voltei a estudar, para completar os meus estudos e depois desisti porque engravidei e tive que criar minha filha. Não tinha tempo para estudar. Era mãe solteira e as dificuldades eram muito grandes. Não tinha perspectiva de jeito nenhum de estudar (Egressa Sandra).

Antes de entrar no IFRN, eu era apenas uma dona de casa. Cuidava da casa, do marido, dos filhos. Mas sentia que algo faltava em mim, que algo precisava ser completado. Então voltei para a sala de aula. E descobri isso junto ao IFRN, com o curso do PROEJA que me qualificou e me tornou a profissional que sou hoje (Egressa Shirley).

A fala das egressas deixa clara a realidade enfrentada por inúmeras mulheres que, ao engravidar, se vêem obrigadas a optar pelos cuidados dos filhos e do lar. Realidade diretamente relacionada às expectativas e encargos que a sociedade historicamente tem atribuído as mulheres.

Hoga et al. (2010) discute sobre esse contexto e corrobora com o sobredito ao apontar que as mulheres são, muitas vezes, as únicas responsabilizadas por suas gestações e, portanto, as únicas que devem arcar com o preço de suas escolhas. Nesse caso, a escolha de ser mãe e, consequentemente, cuidadora. Devendo disponibilizar prioridade para os cuidados com filhos e família, deixando em segundo plano outros desejos, como é o caso dos estudos.

Castro e Barreiro (2017) reforçam esse contexto ao tratarem sobre a importância da família na interrupção dos estudos. A pesquisa desenvolvida pelas autoras aponta que a maternidade, e os sentidos atribuídos a ela, se apresentam como fator decisivo para a ocorrência de abandono dos bancos escolares, uma vez que trabalho doméstico e cuidados com a família são colocados como funções prioritárias da mulher. 
Em suma, Madureira, Morais e Jacome (2018) enfatizam que a questão do abandono e adiamento dos estudos, por parte de mulheres, em sua maior parte apresenta ligação direta com expectativas sociais enraizadas no tocante ao comportamento e ao papel que as mulheres devem exercer na sociedade.

\subsection{Dificuldades e Preconceitos}

Para tratar sobre as dificuldades enfrentadas no retorno ao ambiente escolar, é importante que antes lancemos uma breve problematização sobre os sujeitos a quem nos referimos. No caso da EJA sujeitos jovens e adultos e sobre eles, de acordo com Almeida e Corso (2014, p.84) se pode inferir que:

Uma característica frequente do jovem e adulto é sua baixa autoestima, muitas vezes reforçada pelas situações de fracasso escolar. A sua eventual passagem pela escola, muitas vezes, foi marcada pela exclusão e/ou pelo insucesso escolar. Com um desempenho pedagógico anterior comprometido, jovem e adulto trabalhador volta à sala de aula revelando uma autoimagem fragilizada, expressando sentimentos de insegurança e de desvalorização pessoal frente aos novos desafios que se impõem.

Ao retornarem ao ambiente escolar, com as características acima explicitadas, os jovens e adultos apresentam-se vulneráveis e essas fragilidades também foram marcas da trajetória dos egressos entrevistados, como é possível visualizar nas seguintes falas:

Eu não tinha hábito de mexer em computador. Quem fez a minha matrícula foi o rapaz lá que eu pedi a ele para fazer. Ele disse: "Sente ali no computador e se inscreva" e eu disse "Não moço, eu não sei". E ele disse: "Eu vou dizendo e você vai fazendo". Até hoje brinco com ele dizendo que dei trabalho, mas estou muito satisfeita. Minha maior dificuldade foi a informática, tanto que reprovei nessa matéria (Egressa Sandra).

A dificuldade que tínhamos era que a turma era bem mesclada. Tinha gente de várias idades e gente havia saído do ensino médio há bastante tempo. Então a dificuldade era encontrar um meio-termo em relação aos alunos e alguns preconceitos em relação ao PROEJA (Egresso Flaviano).

Já no tocante a existência de preconceito que, segundo Castilho (2009), fundamenta a discriminação, isto é, a ocorrência de tratamentos desiguais para com indivíduos que pertencem a um grupo ou categoria particular, a fala da egressa Shirley aponta que o preconceito foi uma realidade enfrentada.

Em termos de preconceito, existe sim. Primeiro porque as pessoas não acreditam que pessoas com idade um pouco mais avançada possam estar na sala de aula e conseguindo seus objetivos: Uma formação, uma qualificação, mercado de trabalho. Então existe sim o preconceito que vem da sociedade, mas eu venci esse preconceito porque eu já tinha mais de 30 anos quando comecei o PROEJA e a cada dia que passava eu via que eu me superava e conseguia atingir meus objetivos e isso foi me estimulando cada vez mais para que eu concluísse o curso e atingisse meus objetivos (Egressa Shirley).

Castilho (2009) aponta que esse contexto é, muitas vezes, fruto de diferenças construídas ao longo da história, nas relações sociais e de poder, de modo que o outro passa ser tratado como inferior, justificando-se desse modo tratamentos que insistem em ditar regras quanto, por exemplo, a existência de uma faixa etária adequada para cada atividade a ser desempenhado ao longo da vida.

Apesar disso, é importante destacar o papel fundamental desempenhado pelos educadores, como é possível visualizar no fragmento a seguir: 
Os professores sempre nos incentivavam bastante então tivemos apoio dos professores e servidores do instituto, da equipe EJA que nos proporcionou esse conforto dentro do instituto. Nesta parte não tínhamos preconceito com a modalidade EJA. Isso nos ajudou a superar essas dificuldades. Muitos por não conhecerem a modalidade EJA acham que é algo mais simples, fácil. Que você entra e acaba passando, mas são as mesmas dificuldades encontradas no ensino integrado convencional. Por exemplo, temos a mesma carga horária, as mesmas disciplinas e as mesmas dificuldades em relação as disciplinas de ensino médio ou técnicas, ou laboratório. Temos as mesmas funções que os demais. Não é algo simples, é uma modalidade importante que proporciona um diferencial (Egresso Flaviano).

Esse posicionamento destaca a relevância da existência de profissionais da educação que exerçam seus papeis com um viés diferenciador ao atuar com o público da EJA, estando preparados para receber e formar jovens e adultos frutos de uma sociedade marcada por desigualdades, com o olhar sempre direcionado à inovação de metodologias capazes de transformar o ambiente escolar em local mais atrativo, estimulador e acolhedor.

\subsection{Concretização de Sonhos}

Apesar de suas trajetórias serem envoltas por uma série de dificuldades, os entrevistados conseguiram voltar à escola e a partir de suas falas é possível inferir que esse retorno consiste na realização de sonhos.

A opção do IFRN me proporcionaria não somente um ensino médio de qualidade, mas também uma carreira. Sem dúvidas, foi um divisor de águas na minha carreira em relação ao ensino médio e técnico. Através dele eu consegui uma bolsa de estudos numa universidade privada, 100\% gratuita e eu consegui minha formação em engenharia civil e hoje eu consigo trabalhar na minha área. Sou servidor público em Aracati/CE e trabalho na área decorrente do curso técnico do IF. Foi algo excepcional na minha vida (Egresso Flaviano).

Como eu morava em Mossoró eu procurei o IFRN porque era a instituição que poderia me dar o curso que eu queria fazer, na área de construção civil. E como eu via que Mossoró estava crescendo, e eu queria crescer junto com a cidade. Eu via que ia ter muito desenvolvimento na cidade. Eu procurei o curso de edificações para essa formação que eu tenho hoje. A EJA é uma oportunidade que todos devem abraçar. Especialmente quem já tem idade avançada ou estão fora do mercado de trabalho deve sim fazer parte da EJA porque a EJA é um grande aprendizado. E hoje estou aqui, uma mulher no mercado de trabalho que trabalha na construção civil. Sou encarregada de manutenção. Poucas mulheres ocupam essa posição hoje, mas dou graças a Deus por estar nesse lugar por conta da EJA. Coordeno mais de 50 e isso para mim é um privilégio, um orgulho. As pessoas que me veem hoje me dizem: "Eu não acredito que você está na posição que está” e tudo eu devo às oportunidades do PROEJA e é muito importante que as pessoas acreditem que podem conseguir. Isso é o mais importante. Você entra mas você tem que seguir seus objetivos acreditando que você pode ser melhor hoje e amanhã (Egressa Shirley).

Sempre fui louca por edificações. Dizia: Meu Deus! Se eu tivesse condições de fazer um curso desses... Então procurei me informar e fiquei sabendo que lá tinha edificações. Fiz de tudo para entrar. E eu já vivia insatisfeita porque chegava do trabalho cansada. Dizia: "Essa não é a vida que quero para mim, trabalhar, chegar cansada e dormir". Ás vezes eu pegava no sono na cadeira sem jantar. O que aconteceu: Como estava insatisfeita, mudei a minha mente, minhas atitudes e procurei. Em muitos aspectos o PROEJA tá na vida da gente e nos oferece condições de crescimento. Se você quiser crescer. Você cresce porque o corpo docente é muito bom. Lá tem muitas condições de crescer. $O$ que eu posso dizer para um jovem que está desestimulado e acha que não tem idade para estudar é que não existe idade certa quando queremos fazer algo. Sonhou e correu atrás, você consegue! As minhas dificuldades foram superadas. Eu agreguei esse conhecimento. Graças a Deus me sinto orgulhosa de ter entrado nesse título, pois pude fazer um ensino médio bom. Não tínhamos condições de fazer um bom ensino médio e ainda ter o curso técnico para ter uma profissão e me dar condições de entrar numa faculdade que eu tanto almejo que é Arquitetura e Urbanismo. São coisas que amo. Não tem nada melhor na vida do que fazer algo que amamos. Isso é muito 
importante. Significa tudo. Significa conhecimento, crescimento. Muda nossa mentalidade. Temos a oportunidade de conviver com todo tipo de pessoa e isso agrega valores a sua vida através de todo o conhecimento que o EJA oferece. Abriu portas grandiosas para o meu crescimento porque me deu chaves para ir muito além (Egressa Sandra).

Esses fragmentos só reforçam que, apesar de todos os entraves existentes, é indiscutível a relevância do papel desempenhado pelo PROEJA ao favorecer uma formação mais completa, até então negada pelo Estado que historicamente desenvolveu as práticas educativas aos jovens e adultos de forma dual.

Se por um lado o contexto social foi fator responsável pelo distanciamento dos participantes das salas de aula, no fim das contas foram as circunstâncias que os fizeram enxergar a volta aos estudos como uma forma de transformações de suas realidades.

Contudo, vale salientar que a visibilidade e o reconhecimento não são suficientes, ainda é necessário que os institutos sigam trilhando caminhos que se destinem ao investimento da construção de espaços mais justos e igualitários. E que mais Sandras, Shirleys e Flavianos venham a ter oportunidades de mudar de vida por meio de uma educação de qualidade.

Como forma de validar o curta-metragem, desenvolvido anteriormente, essa pesquisa contou com o desenvolvimento de rodas de conversa em formato virtual com alunos do $2^{\circ}, 4^{\circ}, 6^{\circ}$ e $8^{\circ}$ do Curso Técnico em Edificações na modalidade PROEJA do IFRN - Campus Mossoró.

As rodas foram espaços introdutórios para realização da validação, configurada como espaços abertos para que alguns alunos pudessem falar acerca de suas trajetórias escolares e das suas dificuldades no PROEJA do IFRN e, após sua finalização, os participantes pudessem assistir a exibição do curta-metragem "Construindo História: Narrativas dos alunos egressos do PROEJA no IFRN - Campus Mossoró".

Após a exibição, nos preocupamos em realizar um breve debate sobre os aspectos mencionados no vídeo, como forma de direcionar os alunos ao próximo passo, que consistiu em responder ao questionário semiestruturado, disponibilizado no Google Forms, plataforma online que oferece suporte para a criação de formulários personalizados, cujos resultados serão apontados a seguir.

É necessário destacar a importância do conhecimento da realidade socioeconômica dos indivíduos pesquisados, recorrendo à utilização da pesquisa social que, para Gil (2008, p.45), pode ser definida como 'o processo que, utilizando a metodologia científica, permite a obtenção de novos conhecimentos no campo da realidade social".

Ainda de acordo com o autor, essa realidade social, compreendida em seu sentido amplo, apresenta-se envolta em aspectos relativos ao homem em seus diversos relacionamentos, sendo possível inferir que os sujeitos são uma composição ampla de todos os fatores que os cercam. Nesse sentido, ao longo dessa seção estaremos dialogando com os dados coletados, expostos nos gráficos a seguir.

No que diz respeito à faixa etária, dos 30 participantes, 32\% responderam ter entre 19 e 25 anos, $13 \%$ entre eles têm entre 26 e 30 anos, outros $29 \%$ apresentam idade entre 31 e 40 anos, enquanto $26 \%$ possuem idade superior a 40 anos.

Sampaio (2002), em seu estudo sobre sincronismo entre idade e série aponta que teoricamente o sincronismo ideal estabelece que os alunos com 15 anos de idade devem estar cursando a $1^{\text {a }}$ série do ensino médio, desse modo, a idade ideal para finalização do ensino médio seria entre 17 e 18 anos, a depender se o ensino médio o que normalmente vemos em escolas públicas com duração de três anos, ou se seria na modalidade integrada ofertada pelos Institutos Federais com prazo de duração de quatros anos.

A partir desses dados é possível depreender que os alunos dessa modalidade se situam em uma categoria de desconformidade entre idade/série, ou seja, alunos que após trajetórias marcadas por evasões, não apresentam idade compatível com aquela considerada adequada à série.

Com isso é possível inferir que os sujeitos em alguma etapa da vida tentaram uma articulação entre o fluxo da vida e a 
escola, sem êxito, revelando a incompatibilidade existente entre as trajetórias de vida e a lógica de estruturação do sistema escolar.

No tocante a identidade de gênero, tivemos um percentual de 59\% de participantes mulheres e $41 \%$ de participantes homens.

Os dados nos possibilitam identificar as mulheres como maioria e elas não são maioria somente aqui. Silva (2020) aponta que as mulheres têm se apresentado como maioria entre os trabalhos precarizados. Maioria na ocupação de funções mais rotineiras e sem necessidade de maior qualificação. Além disso, as mulheres também aparecem sendo as mais exploradas no espaço privado, uma vez que, historicamente, têm sido responsabilizadas pela realização dos trabalhos domésticos e não remunerados.

O contexto em tela expõe, portanto, que as mulheres são as que mais sofrem com as vulnerabilidades advindas da dinâmica social. Para esse público, o retorno é ainda mais difícil. "Muitas mulheres vivem problemas de duplas jornadas e, também, de assumirem sozinhas a chefia da família uniparental, em que a mulher garante o sustento e a educação dos filhos com o trabalho, sem que, muitas vezes, possa educar-se, seja pelo tempo escasso, seja pelos horários de oferta inadequados à realidade de vida dessas famílias"' (Brasil,2008, p.08).

Partindo para captação de dados referentes à inserção no mundo do trabalho, os dados apontam que 55\% dos participantes trabalham, enquanto $45 \%$ encontram-se desempregados.

Essas informações são pontes para questionamentos pertinentes para se compreender a realidade desses sujeitos. Um coletivo formado por jovens e adultos, vivência na EJA uma dualidade determinante para a sua permanência: a inserção ou ausência no mundo do trabalho.

Os participantes fazem parte da classe operária, também denominada como proletariado, que, segundo definição de Engels (1888), trata-se da classe de assalariados que, por não possuir meios de produção, vendem sua força de trabalho como forma de produzir sua subsistência. Em outras palavras, são sujeitos provenientes das classes menos favorecidas. São produtos da desigualdade social que permeou e permeia a sociedade brasileira.

Essa realidade pode ser ratificada a partir dos dados frutos do questionamento que teve o intuito de captar informações concernentes à renda familiar mensal dos participantes. Onde 69\% afirmaram possuir renda mensal de até um salário-mínimo, $31 \%$ alegaram possuir renda de até dois salários-mínimos, enquanto a opção que destinada aqueles cuja renda girasse em torno de três a cinco salários não foi selecionada, ou seja, nenhum dos participantes possui renda de três a cinco salários-mínimos.

Nossos dados são corroborados por Ramos et al.(2020) que avaliam em sua pesquisa que este público se constitui de número equilibrado entre homens e mulheres, pessoas em sua maioria pretas e pardas em idade produtiva, porém, de uma realidade socioeconômica de baixa renda.

Para análise desses dados é importante entender a conjuntura atual. Para Frigotto (2001), a realidade atual se consiste enquanto sociedade capitalista, que tem constantemente se revelado contra a humanidade e apresentado a eliminação dos direitos sociais conquistados ao longo da história pela classe trabalhadora como uma de suas marcas principais.

Levando em consideração essa conjuntura e sabendo que os retrocessos ocorrem principalmente, no considerado o tripé da seguridade social (Assistência Social, Saúde e Previdência), é possível inferir que o valor atual do salário-mínimo é insuficiente para suprimento das necessidades geradas pela série de desmontes dessas políticas sociais.

O Departamento Intersindical de Estatísticas e Estudos Socioeconômicos (2021), ratifica a perspectiva supracitada ao apontar que, em fevereiro, o salário-mínimo necessário para sustentar uma família de deveria ter sido de $\mathrm{R} \$ 5.375,05$. O valor é quase 5 vezes o salário-mínimo em vigor atualmente, de $\mathrm{R} \$ 1.100,00$.

Outro aspecto que pode ser somado a essa realidade diz respeito ao número de sujeitos que possuem filhos. Do total de participantes, $66 \%$ afirmaram ser pais/mães e $34 \%$ declararam não ter filhos. 
Os dados supracitados demonstram que a maioria dos participantes tem que cumprir com a responsabilidade de prover o sustento necessário ao atendimento das necessidades básicas de suas famílias. Corroborando com a realidade apresentada por documentos oficiais que apontam que o público da modalidade de educação para jovens e adultos, em sua maioria, são pessoas que vivem no mundo adulto do trabalho e que possuem responsabilidades sociais e familiares (Brasil, 2006).

Dando continuidade e, com o intuito de captar aspectos referentes ao deslocamento de suas residências até a instituição onde estudam, nos deparamos com uma realidade que merece atenção. Apesar da maioria, $76 \%$ dos participantes, residir no município de Mossoró, os outros $24 \%$ afirmaram residir em outros municípios, mais especificamente $4 \%$ na cidade de Areia Branca, 17\% em Governador Dix-Sept Rosado e 3\% no município de Grossos.

Esses dados expressam que, de forma muito evidente, além as dificuldades advindas da conciliação trabalho/estudos, outros fatores também fazem parte do universo de dificuldades que os discentes têm que enfrentar para permanecer estudando, como é o caso da distância entre sua casa e a instituição.

Diante dessa realidade, nos preocupamos em destinar um espaço para tratar sobre mais experiências e conseguir tratar de maneira mais detalhada sobre as principais barreiras enfrentadas por esses sujeitos.

Demos início à tentativa de conhecer mais de perto as barreiras enfrentadas pelos participantes abrindo espaço para que eles falassem sobre suas experiências escolares que antecederam o ingresso no PROEJA do IFRN - Campus Mossoró O quadro a seguir demonstra algumas dessas considerações, e como forma de preservar a identidade dos participantes os registros serão identificados como Participante I, II, III, IV, V, VI, VII, VIII, IX, X.

Quadro 2 - Experiências escolares anteriores.

\begin{tabular}{|c|c|}
\hline Participante I & $\begin{array}{l}\text { "Não tive uma experiência muito boa, pois estudava numa escola estadual aonde os } \\
\text { professores já vinham de outro trabalho cansado e muitas das vezes não se preocupavam se } \\
\text { os alunos tinham entendido o assunto". }\end{array}$ \\
\hline Participante II & "'Experiências ruins, educação cheia de dificuldades". \\
\hline Participante III & "'Sempre em escola pública e cursei até o ensino médio, mas não conclui'”. \\
\hline Participante IV & $\begin{array}{l}\text { "'Cursei um ano do ensino médio em escola pública e abandonei os estudos, pois tive que ir } \\
\text { trabalhar". }\end{array}$ \\
\hline Participante V & $\begin{array}{l}\text { "Na minha cidade não tem escolas com boa estrutura escolar, e sempre tinha falta de } \\
\text { professores". }\end{array}$ \\
\hline Participante VI & “'Minha experiência foi pouca produtiva por ser a noite na época trabalhava era cansativo'". \\
\hline Participante VII & "'Ensino básico, tinha falta de professores, o ensino não era de qualidade". \\
\hline Participante VIII & $\begin{array}{l}\text { "Um ensino mediano, por ser público, tínhamos dificuldade com alguns professores já que } \\
\text { muitas vezes faltavam as aulas". }\end{array}$ \\
\hline Participante IX & "Minhas experiências eram boas. Graças a Deus eu conseguir ir bem nas matérias". \\
\hline Participante X & "'Ensino precário"'. \\
\hline
\end{tabular}

Fonte: Autores (2021).

Também nos preocupamos em entender os motivos que fizeram com que os participantes, em algum momento de suas vidas, dessem pausa em seus estudos. O quadro abaixo mostra os apontamentos, identificados como motivos: 
Quadro 3 - Causas motivadoras de desistência.

\begin{tabular}{|c|c|}
\hline Motivo I & 'Tive que para os estudos para trabalhar'. \\
\hline Motivo II & "'Dificuldades financeiras"'. \\
\hline Motivo III & "'Fui mãe aos 17 anos e precisei trabalhar para manter meu filho"'. \\
\hline Motivo IV & "Perdi minha mãe muito jovem, e para me manter tive que ir trabalhar". \\
\hline Motivo V & "'Tive que trabalhar para sustentar minha família". \\
\hline Motivo VI & $\begin{array}{l}\text { 'Eu passei um bom tempo sem querer nada com a vida, acabei me envolvendo } \\
\text { com o mundo das drogas, mas graças a deus eu me livrei disso, comecei trabalhar e não tinha } \\
\text { como estudar e trabalhar ao mesmo tempo'. }\end{array}$ \\
\hline Motivo VII & "Me casei logo fui mãe e daí não deu mais para continuar". \\
\hline Motivo VIII & "Sai de minha cidade natal pra passar as férias aqui e acabei casando'. \\
\hline Motivo IX & "'Devido uma gravidez na adolescência'. \\
\hline Motivo X & "'Infelizmente, repeti de ano"'. \\
\hline
\end{tabular}

Fonte: Autores (2021).

As justificativas apontam uma mistura de fatores internos e externos aos indivíduos, indo desde causas como repetência de série até problemas de ordem pessoal como gravidez, casamento, drogas e/ou necessidade de inserção no mundo do trabalho, principal influência sobre a decisão de abandono, sobretudo para os indivíduos com maiores problemas familiares ligados as finanças.

Essa realidade vai ao encontro do pensamento de Ceratti (2007), ao apontar que o fracasso escolar é produto de interações de três tipos de determinantes, a saber: psicológicos, socioculturais e institucionais. Somado a esses três fatores aqueles ligados à economia e à política (Brasil, 2006).

Esse cenário reforça a especificidade do público da EJA como sujeitos que, histórico e diariamente, tem que enfrentar dificuldades dos mais diversos aspectos para permanecer estudando.

Para tratar sobre o retorno as salas de aulas é relevante, primeiramente, contextualizar um pouco acerca do que representa os estudos dentro da nossa sociedade. Conforme aponta Nepomuceno et al. (2019), para a sociedade da qual fazemos parte, estudar representa ascender social e financeiramente, uma vez que esse caminho, geralmente, é capaz de promover uma melhor colocação no mercado de trabalho.

Dos motivos para o retorno aos estudos na EJA, houve o predomínio da opção de melhoria nas condições profissionais e, consequentemente, de vida. Dados esses resultados, é possível inferir que é um público motivado a estudar e que enxergam a educação como caminho capaz de proporcionar melhores condições de vida.

As representações caminham em direção ao que Negreiros et al. (2017) afirma: que os alunos da EJA, ao se sentirem insatisfeitos com suas condições atuais, planejam um novo futuro. Nesse sentido, seus projetos direcionam-se ao amparo a suas famílias e ao desenvolvimento pessoal e profissional, no intuito de alcançar melhor condições financeiras e ascensão social.

Após conhecer mais de perto a realidade dos participantes, também nos preocupamos em captar seus pontos de vista acerca do PROEJA. Para isso lançamos dois questionamentos, o primeiro almejando depreender suas expectativas anteriores à exibição do curta-metragem e o segundo com o intuito de averiguar se o produto educacional foi capaz de proporcionar alguma mudança sobre o pensamento inicial.

é possível verificar uma dualidade. De um lado, algumas concepções demonstram que os discentes do PROEJA compreendem a função do programa, explicitada no Documento Base como "atender à demanda de jovens e adultos pela oferta de educação profissional técnica de nível médio, da qual, em geral, são excluídos, bem como, em muitas situações, do próprio ensino médio" (BRASIL, 2007, p.12).

Por outro lado, temos apontamentos que refletem a existência de preconceitos e uma visão da formação oferecida apenas como algo pontual e sem perspectivas e sem possibilitar transformações, sendo, portanto, esse o público que mais 
intencionamos tocar com a produção do curta-metragem.

A partir das falas dos participantes é possível visualizar que, de forma unânime, o curta-metragem serviu como fonte de inspiração. Isso fica nítido em suas colocações que apontam como palavras-chave em seus discursos os termos: "incentivo" e "motivação"

Desse modo, é possível inferir que o trabalho cumpriu com seu papel social ao proporcionar esperança a sujeitos que historicamente tem sido colocado a margem da sociedade. Contudo, mesmo diante de uma avaliação positiva, sabemos que não se esgota aqui. Por isso, consideramos necessária a luta constante pela construção de uma educação de jovens e adultos de forma humana e integral.

Para isso é necessário levar em consideração que as trajetórias dos discentes da EJA/EPT (PROEJA), conforme aponta Moll (2010), consiste em uma bagagem de sonhos uma vez que esses estudantes vêm carregados com sonhos de família, sonhos de trabalhos dignos, sonhos de consumo, sonhos de ir além.

\section{Considerações Finais}

A trajetória da educação brasileira, mais especificadamente, a Educação de Jovens e Adultos (EJA) é marcada por diversas fases, cada uma delas com suas especificidades, e em íntima relação com os diversos contextos sociais, políticos e econômicos pelos quais o país atravessou no curso da sua história.

Durante décadas, a EJA serviu como ferramenta de perpetuação de poder pela classe dominante. Fato que nos faz analisar e compreender a motivação para diversos tipos de programas aligeirados e campanhas de alfabetização superficiais que marcaram sua trajetória. Com o objetivo único e exclusivo de atender as urgentes demandas de mercado.

Somente na história mais recente a EJA apresenta uma nova forma que busca ir além da sua característica como política meramente compensatória. De acordo com as Diretrizes Curriculares Nacionais para a EJA (2000), a escola apresenta três funções a serem assumidas. A primeira é a função reparadora, que se apresenta como tentativa de mudança da injusta realidade da EJA. A função equalizadora, vislumbrando uma melhor inserção na sociedade e no mercado de trabalho por meio da oferta de educação de forma igualitária. E por fim, a função qualificadora, que pode ser considerada para além de uma função, ela é o sentido da EJA. Voltando-se ao apelo para uma educação universal, solidária, igualitária e diversificada.

Apesar dos avanços ocorridos é importante ressaltar que, conforme nos coloca Costa (2013), voltar o olhar para a educação em sua modalidade para jovens e adultos implica tratar sobre o percurso de sujeitos que, em sua maioria, são trabalhadores-alunos cuja formação ocorre no interior de uma sociedade marcada pelas mais diversas expressões da questão social.

Por meio dos resultados da pesquisa e das análises realizadas, percebemos que as falas dos discentes apontam para uma conformidade com esse contexto, de maneira geral, envoltos por dificuldades de permanência na escola. Sabemos que a evasão escolar é uma temática recorrente quando se discuti a EJA, e merece também ser estudada no âmbito do PROEJA, visto que das causas motivadoras para o afastamento desses alunos de um ambiente de sala de aula o trabalho e a família aparecem como pontos fortes

Destarte, observamos a indissociabilidade entre educação e trabalho, na formação humana e profissional de jovens e adultos em situação de defasagem escolar. Principalmente agora, como nos aponta Antunes (2020), em um contexto de crise estrutural do mundo do trabalho, e pior ainda, desmonte e proteção ao pleno emprego e aos direitos trabalhistas. Realidade que vem empurrando uma grande leva de trabalhadores para serviços Uberizados e precarizados. Sem falar no grande exército de reserva que essa realidade tem formado.

Acerca disso, concordamos que EJA mais do que nunca, precisa de fortes e consolidadas políticas educacionais, que atenda não só as demandas dos seus alunos-trabalhadores por escolarização e formação profissional, mas que acima de tudo, os 
coloque em plenas condições de lidar com as crescentes especificidades do mundo trabalho em fase ao colossal avanço e desenvolvimento tecnológico.

E para esse intento, vislumbramos ser o PROEJA um caminho possível para essa formação humana e integral, que poderá possibilitar a efetiva inclusão social e o pleno exercício da cidadania de milhares de jovens e adultos trabalhadores, que em idade escolar foram excluídos não só de um ambiente de sala de aula, bem como um futuro de melhores inserções ao mundo do trabalho.

Ademais, verifica-se muitos desafios a serem superados no PROEJA, porém identificamos pontos positivos no tocante á possibilidade da formação humana integral, que contempla os vários saberes, a saber, trabalho, ciência e cultura, visando a superação de uma concepção pedagógica que restringi a educação da classe trabalhadora as necessidades do mercado. Acreditamos que a continuidade de pesquisas como essa, em torno de discursões sobre a EJA é ferramenta fundamental para que mais propostas como o PROEJA possam surgir.

Desse modo, os achados desse trabalho nos levam a inferir que o PROEJA tem ido ao encontro de sua inserção e consolidação enquanto política pública, corroborando com a possibilidade de formação ampla, inclusão social e o pleno exercício da cidadania de milhares de jovens e adultos espoliados socialmente.

Logo, as narrativas dos egressos do curso de Edificações na modalidade EJA do IFRN, Campus, Mossoró, evidenciaram os sentidos de formação profissional a partir de um Ensino Médio Integrado, principalmente para os alunos das turmas de PROEJA, com quem foi aplicado o curta-metragem: CONSTRUINDO HISTÓRIA: NARRATIVAS DOS ALUNOS EGRESSOS DO PROEJA NO IFRN CAMPUS MOSSORÓ. Para eles, o PROEJA, assume sentidos relacionados a novas oportunidades de escolarização, formação profissional, realização pessoal e perspectiva de melhoria de vida no futuro, após a conclusão do curso.

Consideramos que o trabalho de cunho reflexivo, proporcionado pelas narrativas dos egressos do PROEJA, colaborou para o processo de formação dos estudantes trabalhadores que se encontram cursando o Curso de Edificações na modalidade EJA. Pois permitiu um novo olhar para a formação de jovens e adultos, na medida em que se viram no centro da sua formação, através das histórias de transformação social dos alunos egressos do mencionado curso.

Por isso, vale ressaltar e considerar as histórias de vida como um trabalho formativo, na medida em que permite de um lado contar sua história e do outro refletir e se reconhecer na história narrada. Visto as relações sociais e históricas as quais os indivíduos estão imersos. Nas duas fases da pesquisa, a saber: a construção do curta-metragem com as narrativas dos egressos do PROEJA e sua exibição para os alunos do programa mencionado, percebemos que um dos aspectos fundamentais com esse tipo de pesquisa é o envolvimento intersubjetivo que ela promove.

Percebemos isso, quando os participantes falaram abertamente sobre sua trajetória escolar e suas experiências no PROEJA do IFRN, Campus Mossoró. Sentindo-se encorajados e motivados a revelarem suas histórias de vida a partir das narrativas dos três egressos do curso. As mudanças alcançadas expressaram-se nos discursos dos alunos que se dispuseram a falar durante as rodas de conversas, evidenciando o novo sentido dado a formação humana e profissional proposta pelo PROEJA. Novas perspectivas foram construídas pelos alunos em relação ao PROEJA, a partir dessa intervenção como: a possibilidade de retorno a um ambiente escolar de qualidade, uma formação profissional para inserção ao mercado de trabalho, e a quebra de preconceitos, de si próprios e da sociedade de maneira geral, a partir de uma nova visão em relação à Educação de Jovens e Adultos, adquirida na reflexão sobre sua própria história de vida.

\section{Agradecimentos}

Agradecemos ao Prof. Dr. Samuel de Carvalho docente do IFRN Campus Mossoró/RN pelas importantes contribuições na discussão para a confecção do trabalho dissertativo, que culminou com a materialização desse artigo. 


\section{Referências}

Almeida, A., \& Corso, Â. M. (2015) A Educação de Jovens e Adultos: aspectos históricos e sociais. In: Congresso Nacional de Educação, 12., 2015, Anais [...]. PUCPR, 1283-1299. https://educere.bruc.com.br/arquivo/pdf2015/22753_10167.pdf.

Araújo, M. M. (2017) A trajetória da educação no Brasil na perspectiva da luta de classes. In: Jornada Internacional de Políticas Públicas, 8., 2017, São Luís. Anais [...]. Cidade universitária da UFMA, http://www.joinpp.ufma.br/jornadas/joinpp2017/pdfs/eixo13/atrajetoriadaeduc acaonobrasilnaperspectivadalutadeclasses.pdf.

Brasil. Decreto $N^{\circ}$ 5.840, de 13 de julho de 2006. Institui, no âmbito federal, o Programa Nacional de Integração da Educação Profissional com a Educação Básica na Modalidade de Educação de Jovens e Adultos - PROEJA, e dá outras providências. Brasília/DF: Diário Oficial da União, 2006. http://www.planalto.gov.br/ccivil_03/_ato2004-2006/2006/Decreto/D5840.htm.

Brasil. Lei $\mathrm{n}^{\circ}$. 9.394, de 20 de dezembro de 1996. Estabelece as diretrizes e bases da educação nacional. Brasília, DF: Diário Oficial da União, 1996. http://www.planalto.gov.br/ccivil_03/leis/L9394.htm.

Brasil. MEC. Secretaria De Educação Continuada, Alfabetização E Diversidade. Documento Base Nacional. Secretaria Nacional, Brasília, 2008.

Brasil. MEC. Secretaria de Educação Profissional e Tecnológica. Programa Nacional de Integração da Educação Profissional com a Educação Básica modalidade de Educação de Jovens e Adultos: Educação Profissional Técnica de Nível Médio / Ensino Médio (PROEJA). Documento Base. Brasília: MEC/SEMTEC, 2007.

Brasil. Trabalhando com a educação de jovens e adultos: alunos e alunas da EJA: Caderno 1. 2006.

Bartelmebs, R. C. Analisando os dados na pesquisa qualitativa. In: Metodologias de Estudos e Pesquisas em Educação, 3. http://www.sabercom.furg.br/bitstream/1/1453/1/Texto_analise.pdf.

Cambi, F. (1999) História da Pedagogia. UNESP.

Ceratti, M. R. N. (2007) Evasão escolar: causas e consequências. Gestão Escolar.

DIEESE, Departamento Intersindical de Estatística e Estudos Socioeconômicos. Pesquisa Nacional da Cesta Básica de Alimentos 2021. São Paulo: 5p, 2021.

Gil, A. C. (2008) Métodos e Técnicas de Pesquisa Social. (6a ed.), Atlas.

Godoy, A. S. (1995) Pesquisa qualitativa: Tipos fundamentais. Revista de Administração de Empresas, 35(3), $20-29$.

Haddad, S. (2002) Educação de jovens e adultos no Brasil: 1986-1998. Ministério da Educação e Cultura.

Kaplún, G. (2003) Material educativo: a experiência de aprendizado. Comunicação \& Educação, (27), 46-60.

Le Goff, J. (1990) História e memória. Editora da Unicamp.

Moura, D. H. (2013) Ensino médio integrado: subsunção aos interesses do capital ou travessia para a formação humana integral? Educação e Pesquisa. 39(3), 705-720, http://www.scielo.br/scielo.php?script=sci_arttext\&pid=S1517-97022013000300010\&lng=en\&nrm=iso. Acesso em: 31 de mai. 2020.

Negreiros, F., Silva, C. F. C., Sousa, Y. L. G., \& Santos, L. B. (2017) Análise psicossocial do fracasso escolar na Educação de Jovens e Adultos. Psicologia em Pesquisa, 11(1).

Paula, O. L. B. de, \& Schlaucher, L. (2020) O programa nacional de integração da educação profissional com a educação básica na modalidade de educação de jovens e adultos (PROEJA) a partir do ordenamento híbrido: pesquisa documental. Research, Society and Development, 9(7), e513974284. 10.33448/rsdv9i7.4284. https://rsdjournal.org/index.php/rsd/article/view/4284.

Pollak, M. (1992) Memória e Identidade Social. In: Estudos Históricos, 5(10), 200-212.

Pollak, M. (1989) Memória, Esquecimento, Silêncio. In: Estudos Históricos, 2(3), 3-15.

Ramos, R. L. da S., et al. (2020) O Proeja na Rede Federal de Educação Profissional, Científica e Tecnológica: um panorama dos sujeitos em 2018. Research, Society and Development, 9(8). 10.33448/rsd-v9i8.5988. https://rsdjournal.org/index.php/rsd/article/view/5988.

Sa, R. M. B., Moura, D. H., \& Henrique, A. L. S. (2020) O ensino integrado como medida política em prol da justiça social: o caso dos cursos EFA em Portugal e do PROEJA no Brasil. Rev. Bras. Educ., 25, e250021. http://www.scielo.br/scielo.php?script=sci_arttext\&pid=S1413$24782020000100218 \& \operatorname{lng}=$ en $\& n r m=$ iso.

Sampaio, C. E. M., et al. (2002) Sincronismo idade/série: um indicador de produtividade do Sistema Educacional Brasileiro. Brasília: Inep, (Série Documental. Relatos de Pesquisa. Texto para Discussão, n. 11).

Senado Federal. LDB: Lei de Diretrizes e Bases da Educação Nacional. (3a ed.), Brasília: Senado Federal, Coordenação de Edições Técnicas, 2019.

Silva, A. S. Mulheres na EJA/EPT (PROEJA): uma aproximação a partir das histórias de vida. 2020. Dissertação (Mestrado em Educação Profissional e Tecnológica) - Instituto Federal Sul-Rio-Grandense Campus Charqueadas, Charqueadas. 